\title{
Maxillary Advancement Surgery and Nasolabial Soft Tissue Changes
}

\author{
Dr.Hidayat Nagori ${ }^{1}$, Dr. Tirbod Fattahi ${ }^{2}$ \\ ${ }^{1}$ (Orthodontic, School Of Health Science / Jacksonville, USA) \\ ${ }_{2}^{2}$ (Oral And Maxillofacial Surgery, UF Health/ University Of Florida Jacksonville, USA)
}

\begin{abstract}
Orthognathic surgeries are routinely performed to improve esthetic and function. Predication of soft tissue response to mandibular surgery is more certain than maxillary surgery. Purpose of this study is to identify nasolabial soft tissue changes that occur with the maxillary advancement surgery and to evaluate correlation between hard tissue and soft tissue change.

Materials and Methods : A retrospective study of 35 non growing Class-III adult patients who had le fort -I advancement surgery at Shands hospital Jacksonville were included. All the subjects were diagnosed with maxillary deficiency and treated with least $5 \mathrm{~mm}$ of maxillary advancement surgery. Lateral cephalograms were taken at least one month before and more than 2-3 weeks after the surgical procedure. All the cephlograms were scanned and digitized using dolphin imaging program by a single examiner.

Results: Direct cephlometric measurement on 21 subjects showed 4.5 degree reduction in nasolabial angle but mean changes in NLA were statistically non-significant. T-test also demonstrated statistically significant increase in nasal prominence and upper lip length. Co-relation analysis shows that maxillary advancement is positively correlated with the nasal tip angle with moderate co-relation of 0.492. Maxillary advancement is also co-related with the upper lip length with moderate co-relation of 0.612.

Conclusion: Lefort-I advancement surgery produces increase in upper lip length and nasal tip angle and increase in nasal projection. Nasolabial angle decreases with maxillary advancement but changes are statistically not significant.
\end{abstract}

Keywords: Labial soft tissue change, Maxillary advancement surgery, Naso-Labial angel changes

\section{Introduction}

Primary objective of orthognathic surgery is to improve facial and dental esthetic. Combined orthodontic and surgical procedures are used to correct facial deformities ${ }^{13}$. Improvement in soft tissue appearance is the prime motivating factor for the majority of the patients ${ }^{13}$. Surgical movement of bony segment and orthodontic movement of the teeth both influence overlying soft tissue. Nasal analysis and quantitative data on the surgical movement and soft tissue changes need to be considered during the treatment planning process to predict soft tissue changes that can occur with dental and skeletal tissue alteration after surgery. While lower lip and chin respond in approximately 1:1 ratio to hard tissue movement, the upper lip responds in a ration of 0.3$0.8: 1 .^{3,4,5,11,12}$. Soft tissue changes are more predictable with mandibular surgery than maxillary advancement surgery due to soft tissue variability in midface region.

Many studies have attempted to evaluate relation between surgical movement and overlying soft tissue changes. Vasudhavan et at (2012) did anthropometric study with 37 subjects with mean age of 18.6 year. Direct anthropometry showed that NLA decrease $9.8^{\circ}$, nasal length increased by $1.3 \mathrm{~mm}$ and upper lip moved forward by $4.15 \mathrm{~mm}$. It is clear from the literature review that there is big controversy in nasolabial soft changes that occur after maxillary advancement surgery. Nasal analysis and treatment planning are crucial for the success of orthognathic surgery. Failure to successfully predict soft tissue change that may occur with hard tissue movement may lead to undesirable esthetic outcome. The Purpose of our study was to conduct both cephlometric and anthropometric evaluation of soft tissue changes in skeletal class-III patient treated with maxillary advancement surgery and to established co-relation between hard tissue and soft tissue change.

\section{Review Of The Literature}

Primary objective of orthognathic surgery is to improve facial and dental esthetic. Combined orthodontic and surgical procedures are used to correct facial deformities ${ }^{13}$. Improvement in soft tissue appearance is the prime motivating factor for the majority of the patients ${ }^{13}$. Surgical movement of bony segment and orthodontic movement of the teeth both influences overlying soft tissue. Growth is also major contributing factor with soft tissue change. There for Quantitative data on the surgical movement and soft tissue changes need to be considered during treatment planning process to predict soft tissue changes that can occur with dental and skeletal tissue alteration after surgery. While lower lip and chin respond in approximately 1:1 ratio to hard tissue movement, upper lip responds in ratio of $0.3-0.8: 1 .^{3,4,5,11,12}$. Therefor soft tissue changes are more 
predictable with mandibular surgery than maxillary advancement surgery due to soft tissue variability in midface region.

Many studies have attempted to evaluate relation between surgical movement and overlying soft tissue changes. Vasudhavan et at (2012) did anthropometric study with 37 subjects with mean age of 18.6 year. All subjects went through single piece lefort-I advancement surgery only with rigid fixation. Direct anthropometry showed that NLA decrease $9.8^{\circ}$, nasal length increased by $1.3 \mathrm{~mm}$ and upper lip moved forward by $4.15 \mathrm{~mm}$. Their study included 50\% cleft patient which added outlier to the soft tissue variability for this patient population ${ }^{14}$.

Louis et al evaluated horizontal and vertical soft and hard tissue changes with maxillary advancement surgery. Their research did not demonstrate any significant correlation between maxillary advancement and changes in the nasolabial angle. However they did report that all the patients with maxillary advancement surgery had an average decrease in nasolabial angle of 5 degrees ${ }^{7}$.

Conversely, Freihofer et $\mathrm{al}^{5}$ reports that nasolabial angle (NLA) increases after maxillary advancement surgery. He also concluded that anterior nasal spine influences NLA. He noticed less increase in NLA when anterior nasal spine was removed during surgical procedure ${ }^{6}$. Mansour et al. and Daun et al ${ }^{4}$ found in their study that nasolabial angle decreases with maxillary advancement surgery. Mansour et al also mentioned that the changes in NLA after maxillary surgery are unpredictable. Gassmann $\mathrm{CJ}^{7}$ et al found that specific prediction of changes in nasal morphology after Le fort-I osteotomy is very difficult.

The nose is subjected to huge dimensional changes after le-fort - I surgery. Its been reported that alar base width increases with maxillary advancement and impaction procedure. Ubaya et. Al (2012) used 3D soft tissue analysis to measure soft tissue changes after maxillary advancement surgery. 112 volunteer were included in control group compared with 35 subjects with the maxillary advancement. They reported that the NLA was smaller in both groups but only significant in the female group. They also found increase in width of nasal base. Marsan et $\mathrm{al}^{10}$ found that NLA decrease with lefort - I advancement procedure, upper lip length increases and labiomental angle decreased after surgical procedure.

It is clear from the literature review that there is big controversy in nasolabial soft changes that occur after maxillary advancement surgery. There for purpose of our study was to conduct both cephlometric and anthropometric evaluation of soft tissue changes in skeletal class-III patient treated with maxillary advancement surgery and to established co-relation between hard tissue and soft tissue change. Due to time constrain during residency program this study will be conducted in two parts. First part of the study will include cephlometric evaluation of soft and hard tissue changes and second part of study will include anthropometric evaluation of soft tissue changes.

\section{Material and methods}

A retrospective study of non growing Class-III adult patients who had le fort $-\mathrm{I}$ advancement surgery at Shands hospital Jacksonville were included. All the subjects were diagnosed with maxillary deficiency based on a complete clinical and radiographic evaluation and treated with least $5 \mathrm{~mm}$ of maxillary advancement surgery and no other adjunctive surgical procedure.

Surgical procedure : Standard mucosal incision made between right and left $1^{\text {st }}$ molars followed by Subperiosteal dissection of mid-face and nasal fossa and Subperiosteal dissection of pterygo-maxillary junction. Standard LeFort I osteotomy was performed using reciprocating saw and the osteotomy was reinforced with chisels. Maxilla was down fractured and bony interferences were removed after mobilization of bony segment. Intermaxillary splint was used to repositioned maxilla and maxilla was stabilized using rigid internal fixation. Alar cinch suture to re-establish alar width using double V-Y mucosal closure technique was performed in every subject.

Lateral cephalograms were taken at least one month before and more than two to six weeks after the surgical procedure. All the cephlograms were scanned and digitized using dolphin imaging program by single examiner

To protect patient privacy : Master Code File for the study were created to link Study ID Number with patient name/ medical record number (MRN). Intraoperator reliability was assessed by retracing 10 randomly selected radiographs 3 times by the same examiner. Coefficient of variation was calculated.

\section{Inclusion criteria}

1.1 Single piece Le Fort I advancement surgery with rigid fixation

1.2 Preoperative and at least 6-month postoperative lateral cephalograms available

1.3 No adjunctive nasal procedures performed within the observation period

1.4 Only Non growing class-III subjects

2. Exclusion criteria

2.1 Patient with missing pre-surgical or post -surgical records 
2.2 Patient with poor quality records

2.3 Patient with cleft lip and plate or any other syndromic conditions

2.4 Le-fort - I surgical procedure with multiple piece maxilla

2.5 Cleft lip and palate subjects

Out of 35 subjects received from shands hospital Jacksonville Florida only 20 subjects matched the inclusion criteria and rest of the subjects were excluded from the study. Cephlometric tracing was performed by one examiner only.

\section{Cephlometric analysis}

Cephlometric radiograph were taken at two different time point T1: pretreatment and T2: posttreatment. Radiographs were traced using dolphin imaging software. Nasolabial angle was measured using Fitzgerals's method ${ }^{7}$. Line tangent drawn from posterior columella point (PCm) anterior along lower border of nose. Second line was drown from PCm to labrale superious (ls). Nasolabial angle was measured at the intersection of two lines. NLA can be constructed with high reliability using this method

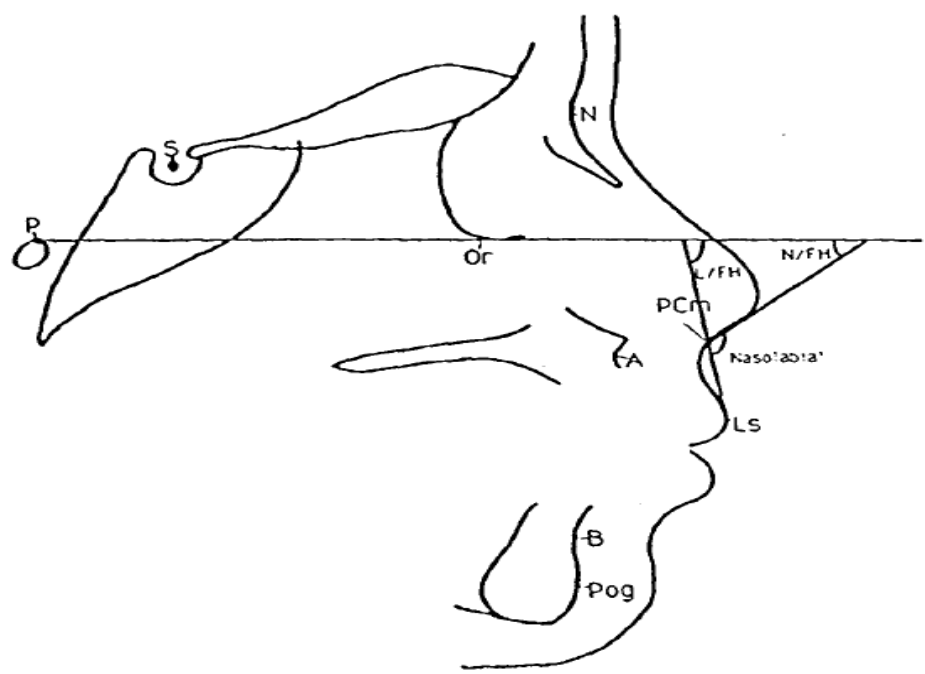

Linear and angular measurement with landmarks

\section{Soft tissue land marks}

Soft tissue glabella ( G'): The most prominent anterior point in midsagittal plane of forhead.

Pronasale (pn) : The most prominent anterior point of the nose.

Soft tissue A point : Depest point on the outline upper lip below subnasale.

Columella $(\mathbf{c m})$ : The lowest point of the soft tissue nasal septum.

Subnasale : The point at which the columella merges with upper lip in midsagittal plane.

Labrale superius (Ls): A point indicating the mucocutaneous border of the upper lip.

\section{Hard tissue landmarks}

Nasion $(\mathbf{N})$ : located on the most anterior aspect of the frontonasal suture.

Sella (s) : Geometric center of the pituitary fossa

Point A: On a line perpendicular to Frankfort horizontal line, located most posterior in the concavity between ANS and maxillary alveolar process.

U1: Most prominent point on the labial surface of upper incisor.

The SN plane was used as horizontal reference plane and line perpendicular to SN through S point was used as vertical reference point. These reference planes were used to calculate different linear and angular measurements.

\section{Angular measurement}

6.1 Nasolabial angle ( Nanda's method )

6.2 Nasal tip angle

6.3 U1- SN

7. Linear measurement

DOI: $10.9790 / 0853-1603082329$ 
7.1 Nasal Heights ( Hollmann : N-sn)

7.2 Nasal prominence ( sn perpendicular - tip of the nose)

7.3 Nasal length ( Sn- pn )

7.4 Nasal projection ( N-tip)

7.5 Upper lip length

7.6 Upper lip thickness

\section{Statistical analysis}

Statistical analysis was performed by the statistician at Jacksonville University School of orthodontics using SPSS software. Paired sample T-test, correlation analysis were performed to assess correlation between soft tissue and hard tissue changes. Regression analysis was used to find if there is any correlation between amount of surgical movement and soft tissue change and also to analyze if we can predict amount of soft tissue changes from hard tissue movement. $\mathrm{R}$ square values were compounded to examine the amount of variance explained by the predictable variable.

\section{Results}

Non growing Class-III adult patients who had lefort -I advancement surgery at Shands hospital Jacksonville were included. All the subjects were diagnosed with maxillary deficiency based on a complete clinical and radiographic evaluation and treated with least $5 \mathrm{~mm}$ of maxillary advancement surgery and alar cinch procedure with no other adjunctive surgical procedure. Out of 35 subjects received from shands hospital Jacksonville Florida only 20 subjects matched the inclusion criteria and rest of the subjects were excluded from the study. Post-operative cephalograms were taken 2-6 weeks after Le fort -I advancement surgery. Cephalometric measurements were performed by only one examiner.

\begin{tabular}{|c|c|c|c|c|c|c|c|}
\hline \multicolumn{8}{|c|}{ Table I Paired Samples Test } \\
\hline & & Mean & Std. Deviation & $\begin{array}{l}\text { Std. } \\
\text { Error } \\
\text { Mean }\end{array}$ & $\mathrm{t}$ & $\mathrm{df}$ & $\begin{array}{l}\text { Sig. (2- } \\
\text { tailed) }\end{array}$ \\
\hline Pair 1 & $\begin{array}{l}\text { T1-NLA - T2- } \\
\text { NLA }\end{array}$ & 4.3450 & 12.5438 & 2.6743 & $\begin{array}{c}1.62 \\
5\end{array}$ & 21 & .119 \\
\hline Pair 2 & $\begin{array}{l}\text { T1-NasalTipAng } \\
\text { - T2- } \\
\text { NasalTipAng }\end{array}$ & -3.3909 & 8.4571 & 1.8031 & $\begin{array}{c}- \\
1.88 \\
1\end{array}$ & 21 & .074 \\
\hline Pair 3 & $\begin{array}{l}\text { T1-U1-SN - T2- } \\
\text { U1-SN }\end{array}$ & -2.4667 & 6.0186 & 1.3134 & $\begin{array}{c}- \\
1.87 \\
8\end{array}$ & 20 & .075 \\
\hline Pair 4 & $\begin{array}{l}\text { T1-NasalHt - T2- } \\
\text { NasalHt }\end{array}$ & 1.0300 & 2.0656 & .6532 & $\begin{array}{c}1.57 \\
7\end{array}$ & 9 & .149 \\
\hline Pair 5 & $\begin{array}{l}\text { T1-NasalProm - } \\
\text { T2-NasalProm }\end{array}$ & 3.4800 & 3.1801 & 1.0056 & $\begin{array}{c}3.46 \\
1\end{array}$ & 9 & .007 \\
\hline Pair 6 & $\begin{array}{l}\text { T1-NasalLength } \\
\text { - T2- } \\
\text { NasalLength }\end{array}$ & .9200 & 2.7300 & .8633 & $\begin{array}{c}1.06 \\
6\end{array}$ & 9 & .314 \\
\hline Pair 7 & $\begin{array}{l}\text { T1-NasalProj - } \\
\text { T2-NasalProj }\end{array}$ & 1.2600 & 2.6018 & .8228 & $\begin{array}{c}1.53 \\
1\end{array}$ & 9 & .160 \\
\hline Pair 8 & $\begin{array}{l}\text { T1- } \\
\text { UpperLipLength } \\
\text { - T2- } \\
\text { UpperLipLength }\end{array}$ & -2.1300 & 2.3504 & .7433 & $\begin{array}{c}- \\
2.86 \\
6\end{array}$ & 9 & .019 \\
\hline Pair 9 & $\begin{array}{l}\text { T1- } \\
\text { UpperLipThick - } \\
\text { T2- } \\
\text { UpperLipThick }\end{array}$ & -1.4000 & 3.0598 & .9676 & $\begin{array}{c}- \\
1.44 \\
7\end{array}$ & 9 & .182 \\
\hline
\end{tabular}




\begin{tabular}{|c|c|c|}
\hline \multicolumn{3}{|c|}{ Table - II Correlations } \\
\hline & & Max Adv \\
\hline \multirow{3}{*}{ DIFF-NLA } & Pearson Correlation & .398 \\
\hline & Sig. (2-tailed) & .083 \\
\hline & $\mathrm{N}$ & 20 \\
\hline \multirow[t]{3}{*}{ DIFF-NasalTipAng } & Pearson Correlation & $.492^{*}$ \\
\hline & Sig. (2-tailed) & 028 \\
\hline & $\mathrm{N}$ & 20 \\
\hline \multirow[t]{3}{*}{ DIFF-U1-SN } & Pearson Correlation & -.350 \\
\hline & Sig. (2-tailed) & .130 \\
\hline & $\mathrm{N}$ & 20 \\
\hline \multirow[t]{3}{*}{ DIFF-NasalHt } & Pearson Correlation & -.077 \\
\hline & Sig. (2-tailed) & .747 \\
\hline & $\mathrm{N}$ & 20 \\
\hline \multirow[t]{3}{*}{ DIFF-NasalProm } & Pearson Correlation & .085 \\
\hline & Sig. (2-tailed) & .722 \\
\hline & $\mathrm{N}$ & 20 \\
\hline \multirow[t]{3}{*}{ DIFF-NasalLength } & Pearson Correlation & -.070 \\
\hline & Sig. (2-tailed) & .770 \\
\hline & $\mathrm{N}$ & 20 \\
\hline \multirow[t]{3}{*}{ DIFF-NasalProj } & Pearson Correlation & -.221 \\
\hline & Sig. (2-tailed) & .350 \\
\hline & $\mathrm{N}$ & 20 \\
\hline \multirow[t]{3}{*}{ DIFF-UpperLipLength } & Pearson Correlation & $.612^{* *}$ \\
\hline & Sig. (2-tailed) & .004 \\
\hline & $\mathrm{N}$ & 20 \\
\hline \multirow[t]{3}{*}{ DIFF-UpperLipThick } & Pearson Correlation & -.302 \\
\hline & Sig. (2-tailed) & .196 \\
\hline & $\mathrm{N}$ & 20 \\
\hline
\end{tabular}

Table 1 shows mean and standard deviation, standard error mean and $\mathrm{P}$ value of soft tissue changes between time point one ( T1) and time point two (T2). Table 1. Shows changes of NLA, Nasal tip angle, Upper incisor angle, Nasal prominence, nasal length, upper lip length and upper lip thickness. There was no statistical significant difference found between most of the angular measurement. The most significant difference in soft tissue variables was observed in nasal prominence $(p=0.007<0.05)$. From paired sample $T$ test it can be concluded that nasal prominence deceases from T1-T2. More over upper lip length increased from T1-T2 with significant value of $\mathrm{p}=0.019<0.05$.

Correlation and regression analysis determined relation between maxillary hard tissue movement and over lying soft tissue response in vertical and sagittal direction. Stronger correlation was found between maxillary advancement and changes in the upper lip length. Upper lip length increased after surgery (Table III) with significant value of $0.004<0.05$. It can be stated that maxillary advancement is positively correlated with upper lip length with moderate correlation of 0.612 . The predictive regression model for the upper lip length is Diff Upper lip length $=-3.934+0.847$ ( $\max$ advancement). One unit of increase in maxillary advancement corresponds with $0.847 \mathrm{~mm}$ increase in upper lip length. There were insufficient evidence to state correlation between maxillary advancement and NLA changes $(P=0.083>0.05)$ although Nasolabial angle decreased with lefort-I advancement surgery. Maxillary advancement procedure is also positively correlate with the difference in nasal tip angle. The predictive regression model for the nasal tip angle is DiffNasal tip angle $=-12.798+2.831$ ( max advancement). One unite increase in the maxillary advancement corresponds with a 2.831 degree increase in nasal tip angle. Rest of the angular and linear soft tissue variable did not show any significant correlation with the maxillary advancement procedure. 
Table III Regression analysis

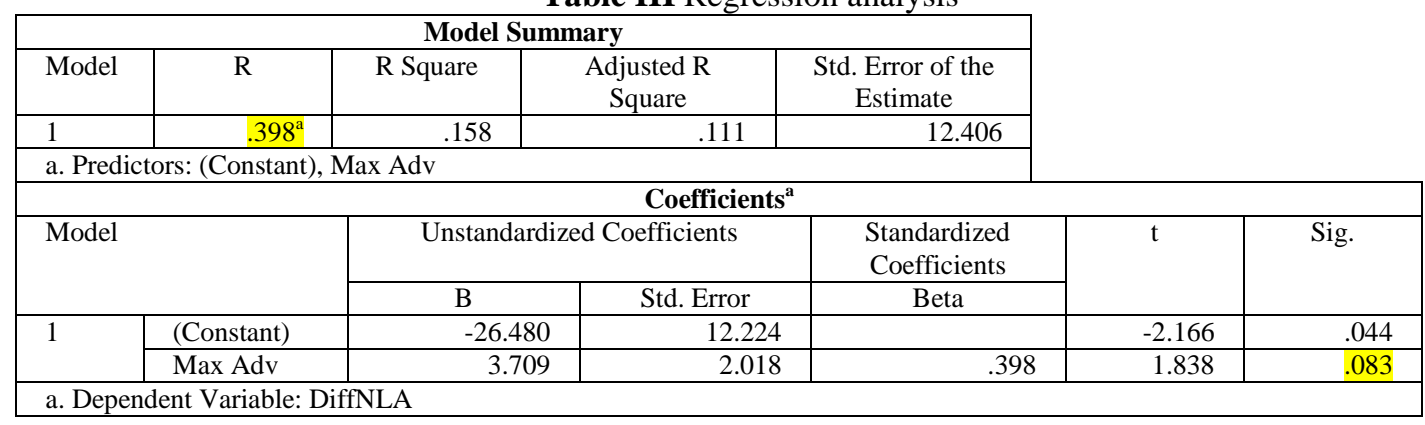

\begin{tabular}{|c|c|c|c|c|c|c|}
\hline \multicolumn{5}{|c|}{ Model Summary } & & \\
\hline Model & $\mathrm{R}$ & R Square & $\begin{array}{l}\text { Adjusted R } \\
\text { Square }\end{array}$ & $\begin{array}{l}\text { Std. Error of the } \\
\text { Estimate }\end{array}$ & & \\
\hline 1 & .492 & .242 & .200 & 7.257 & & \\
\hline \multicolumn{7}{|c|}{ a. Predictors: (Constant), Max Adv } \\
\hline \multicolumn{7}{|c|}{ Coefficients $^{\mathrm{a}}$} \\
\hline \multirow{2}{*}{\multicolumn{2}{|c|}{ Model }} & \multicolumn{2}{|c|}{ Unstandardized Coefficients } & Standardized & $\mathrm{t}$ & Sig. \\
\hline & & B & Std. Error & Beta & & \\
\hline \multirow[t]{2}{*}{1} & (Constant) & -12.7 & 7.151 & & -1.790 & .090 \\
\hline & Max Adv & 2.8 & 1.180 & .492 & 2.398 & .028 \\
\hline
\end{tabular}

a. Dependent Variable: DiffNasalTipAng

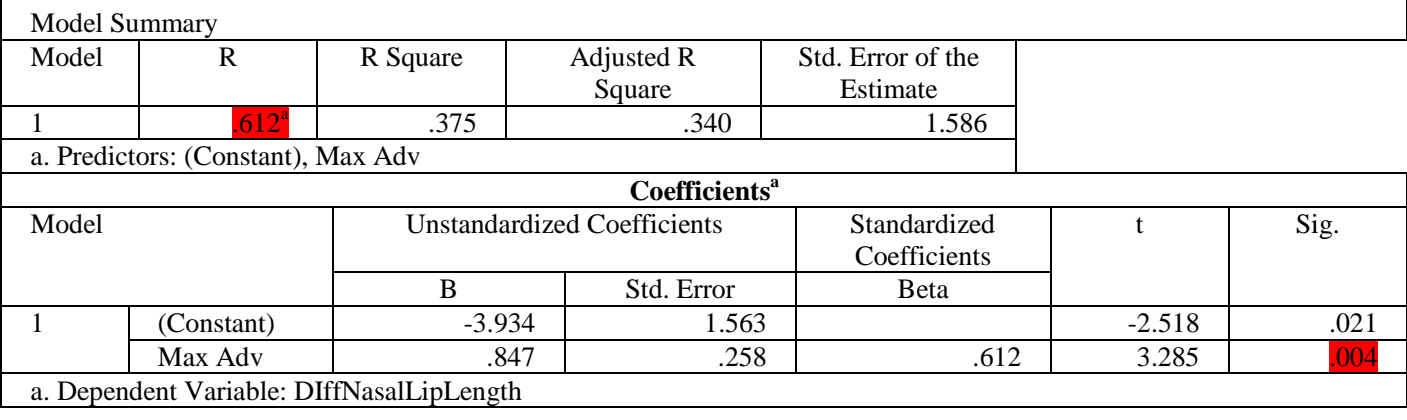

\section{Discussion}

Subjects included in the study presented with severe class-III skeletal discrepancy all the patients in the study were treated with maxillary advancement procedure only. The Primary objective of orthognathic surgery is to improve facial esthetic with secondary objective to improve function. The three dimensional nature of bony structure and characteristic of overlying soft tissue confound the esthetic outcome of orthognathic surgery. Movement of bony structure affects the overall esthetic appearance of the face therefore maxillofacil surgeon must pay close attention to alteration in the facial form before performing orthognathic surgery.

In the current study we measured soft tissue change in twenty class-III non-growing patients using cephlometric radiograph. Linear and angular measurements were performed to evaluate soft tissue changes in the middle and lower third of the face. This study showed that upper lip length was increased after a maxillary advancement procedure. The nasal tip angle increased indicating an elevation of the nasal tip. Similar changes in the nasal tip angle and upper lip have been reported by other studies ${ }^{17}$. Our study indicated that nasal prominence reduces after maxillary advancement that contradicts with other study ${ }^{17}$. Nasolabial angle decreased but changes in NLA were not significant. Changes in NLA were consistent with results reported by other studies $^{7,17}$. Vasudhavan et at (2012) did anthropometric study with 37 subjects with mean age of 18.6 year. Direct anthropometry showed that NLA decreased $9.8^{\circ}$, nasal length increased by $1.3 \mathrm{~mm}$ and upper lip moved forward by $4.15 \mathrm{~mm}$. . Ubaya et. Al (2012) used 3D soft tissue analysis to measure soft tissue changes after maxillary advancement surgery. They reported that the NLA was smaller in both groups but only significant in the female group.

Two dimensional measurement of 3D structure, poor quality of $\mathrm{x}$-ray, error in super imposition, tracing error are some of the main drawbacks of lateral cephlometry. All patient had alar cinch suture to re-establish alar width using double V-Y mucosal closure. Rauso et al reported no changes in the nasolabial angle after alar cinch and V-Y mucosal closure. Post-surgical radiograph were taken 2-6 weeks after orthognathic surgery was performed. However it was not possible to quantify amount if swelling remaining 2-6 weeks after surgery. 
Ideally it is desirable to come up with ratio that can directly predict soft tissue changes form hard tissue movement, but due to significant variation in the soft tissue profile between individuals it will not be possible to accurately measure such changes. In our study we generated a few equations that can be used to predict some soft tissue strictures.

\section{Conclusions}

Lefort one maxillary advancement surgery produces increase in nasal prominence, nasal tip angle and increase in upper lip length. More over increase in upper lip height was observed it could be due to postoperative inflamtion. Nasolabial angle decreased with maxillary advancement surgery but changes in NLA were statistically non-significant. It is import to predict soft tissue changes that can occur with maxillary advancement surgery. Misdiagnosis of soft tissue responses with maxillary advancement surgery can result in undesirable esthetic outcome.

\section{References}

[1]. Altug-Atac, A. T. Facial Soft Tissue Profile Following Bimaxillary Orthognathic Surgery.Angle Orthodontist,2008;, Vol 78, 50-57.

[2]. Bell WH, Profit WR, White RP. Surgical correction of dentofacial deformities. Philadelphia: W. B. Saunders, 1980

[3]. Collins PC, Evker BN. The alar base cinch: A technique for prevention of alar base flaring secondary to maxillary surgery. Oral Surg 1982: 53: 549-53.

[4]. Daun J J, Fonseca RJ, Bell WH. Soft tissue changes associated with total maxillary advancement: a preliminary study. J Oral Surg 1976: 34: 19-23

[5]. Frelhofer P. The lip profile after correction of retromaxillarism in cleft and non-cleft patients. J Maxillofac Surg 1976: 4: 136-41.

[6]. Freihofer HPM. Changes in nasal profileafter maxillary advancement in cleft and non-deft patients. J Maxillofac Surg 1977: 5: 207.

[7]. Fitzgerald, J., \& Nanda, R. An evaluation of the nasolabial angle inclinations of the nose and upper lip and the relative . AM J Orthodontic \& Dentofacial Orthopedic 1992; 102, 328.

[8]. Gassmann CJ, Nishioka GJ, Van Sickels. A lateral cephalometric analysis of nasal morphology following Le Fort I osteotomy applying photometric analysis techniques. J Oral Maxillofac Surg 1989:47: 926-30.

[9]. Louis, P., Austin, B., Waite, P., \& Mathews, C. Soft Tissue Changes of the Upper Lip Associated With Maxillary Advancement in Obstructive Sleep Apnea Patients. J Oral Maxillofac Surg, 2001; 59, 151-156.

[10]. Marsan, G., \& Cura, N. Soft and hard tissue changes after bimaxillary surgery in Turkish female Class III patients. Journal of Cranio-Maxillofacial Surgery, 2008; 37, 8-17.

[11]. Misir, A., Manisali, M., \& Egrioglu, E. Retrospective Analysis of Nasal Soft Tissue Profile Changes With Maxillary Surgery. J Oral Maxillofac Surg 2011, 69, e190-e194.

[12]. Mansour S, Burstor C, LEMAN H. Anevaluation of soft tissue changes resulting from Le Fort I maxillary surgery. Am JOrthod 1983:84: 3747

[13]. Pearlman, S. Surgical Treatment of the Nasolabial Angle in Balanced Rhinoplasty. Facial plastic surgery; 2006; $22,28-35$.

[14]. Rosen HM. Lip-nasal aesthetics following Le Fort I osteotomy. Plast Reconstr Surg 1988: 81: 171-79.

[15]. Rauso R, Tartaro G, Tozzi U, et al: Nasolabial changes after maxillary advancement. J Craniofac Surg 22

[16]. Sakima T, Sacheva R, Soft tissue response to Le Fort I maxillary impaction surgery, tnt J Adult Orthod Orthognath Surg 1987: 4: 221-31.

[17]. T. Ubaya, A. Sherriff, A. Ayoub, B. Khambay: Soft tissue morphology of the nasomaxillaryomplex following surgical correction of maxillary hypoplasia. Int. J. Oral Maxillofac. Surg. 2012; 41: 727-732.

[18]. Vasudavan, S., Jayaratne, Y., \& Padwa, B. Nasolabial Soft Tissue Changes After Le Fort I Advancement. J Oral Maxillofacial Surg, 2012; 70, e270-e277

[19]. Westermark ,AH. Bystedt, H. Nasolabial morphology after Le Fort I osteotomies. Int. J. Oral Maxillofac. Surg. 1991; 20 : 25-30. 